REVISTA X, Curitiba, volume 14, n.4,p. 240-255, 2019

\title{
NEY MATOGROSSO ENTRE BUTLER E FOUCAULT: SOBRE SUJEITOS E SUBVERSÕES DE IDENTIDADES
}

Ney Matogrosso between Butler and Foucault: about subjects and subversions of identities

\begin{abstract}
RESUMO: As análises históricas da sexualidade que Michel Foucault realizou acerca dos modos como o sexo foi visto com o passar dos anos forneceram à Judith Butler a base para a formulação de gênero, sexo e sexualidade não como entidades fixas, mas vistas como construídas e reconstruídas ao longo dos anos em diferentes sociedades e contextos. O presente trabalho parte de análise documental de abordagem qualitativa e visa apreender diálogos e tensionamentos que lancem luzes aos estudos de gênero na atualidade. Para isso, haveremos aqui de nos debruçar sobre o excerto de uma entrevista com o artista Ney Matogrosso. Dessa forma, os autores aqui mobilizados com o intuito de trazer contribuições à discussão da produção de sujeitos pela exterioridade e acerca da (des)construção de identidades.
\end{abstract}

PALAVRAS-CHAVE: estudos de gênero; identidades subversivas; sexualidade.

\begin{abstract}
The historical analysis of sexuality that Michel Foucault held about the ways in which sex was seen over the years have provided the Judith Butler the basis for the formulation of gender, sex and sexuality not as fixed entities, but seen as built and rebuilt over the years in different societies and contexts. This work is part of documentary analysis of qualitative approach and aims to seize dialogues and stresses that launch lights to gender studies today. For this, we shall here to address the excerpt from an interview with artist Ney Matogrosso. Thus, the authors here mobilized in order to bring contributions to the discussion of the production of subject by exteriority and about (un) construction of identities.
\end{abstract}

KEYWORDS: gender studies; Subversive identities; sexuality.

[...] o motivo que me impulsionou é muito simples. Para alguns, espero que ele possa bastar por si só. É a curiosidade; o único tipo de curiosidade que, de qualquer forma, vale a pena ser praticada com um pouco de obstinação: não aquela que busca se assimilar ao que convém conhecer, mas a que permite desprender-se de si mesmo. De que valeria a obstinação do saber se ela apenas garantisse a aquisição de conhecimentos, e não, de uma certa maneira e tanto quanto

\footnotetext{
${ }^{1}$ Doutorando em Linguística pela Universidade Federal de Santa Catarina - CAPES/UFSC. Membro pesquisador do Grupo de Estudos Michel Foucault e os estudos discursivos (UFAM/CNPq) e do Grupo de Formação de Professores em Línguas e Literatura (FORPROLL/CNPq). E-mail: ediliteratus@gmail.com

${ }^{2}$ Doutorando em Estudos Linguísticos pela Universidade Federal de Uberlândia - UFU/FAPEMIG. Membro-pesquisador do Laboratório de Estudos Discursivos Foucaultianos (LEDIF-UFU/CNPq). E-mail: pereira.anisiobatista@ufu.br
} 
possível, o extravio daquele que conhece? Há momentos na vida em que a questão de saber se é possível pensar de forma diferente da que se pensa e perceber de forma diferente da que se vê é indispensável para continuar a ver ou a refletir. (FOUCAULT, 2004, p. 196-197)

Desde o final da década de 80 a Linguística Aplicada $^{3}$ sofreu profundas transformações que perduraram e se intensificaram nos anos 90 cujos efeitos repercutem até hoje. Se nas décadas de 50 e 60 a área esteve voltada para o ensino de línguas, sobretudo no âmbito de países anglófonos onde predomina o uso da língua inglesa ela passou a se voltar para uma nova era caracterizada por novos modos de teorizar e fazer LA (MOITA LOPES, 2006). Essa fase é caracterizada por considerar problemáticas existentes no campo dos estudos de problemas linguísticos que têm relevância no contexto de práticas concretas de uso da língua. $\mathrm{O}$ atravessamento de fronteiras disciplinares frequentemente está presente nessa forma de situar-se teórica e ativamente no mundo. É a partir disso que emergem discussões como a que vamos empreender no presente artigo, ao reconhecer que pensadores distintos oriundos de campos particulares podem contribuir para analisar a complexa rede de práticas sociais linguageiras que nos cercam.

Dessa forma, o presente trabalho pretende trazer reflexões sobre os dizeres e interditos que puderam ser apreendidos a partir do excerto de uma entrevista com o artista Ney Matogrosso. É um trabalho de cunho interpretativo e abordagem qualitativa porque lançamos mão de gestos de interpretação sobre o corpus de análise com auxílio de obras que tratem dos assuntos que podem vir a emergir das reflexões sobre as masculinidades subversivas na atualidade.

Os autores mencionados no decorrer do texto são mobilizados no sentido dialógico (BAKHTIN, 2011) em que os estudos podem fazer refletir e refratar entre si um texto que traz a marca do avesso a iniciar pelo tema. Em Derrida (2005), o fantasma do contrário assola as marcas da identidade (que se impõe por vezes neutralizada e homogênea) mostrando os avessos naquilo que lhe escapa.

Como todo texto escolhe seu leitor, este texto não procura direcionar-se a quem estiver disposto a uma leitura convencional do fenômeno da identidade enquanto algo imerso em tranquilidade e previsibilidade homogeneizadora - conforme criticado por Derrida (2010) -, porque não se busca aqui revelar a harmonia das coisas, mas a subversão, a diferença e a indecidibilidade inerentes nas camadas por trás das certezas

\footnotetext{
${ }^{3}$ LA daqui em diante.
} 
instauradas com o passar do tempo sobre a "verdade" dos assuntos aqui tratados. É um texto que se propõe dialógico no sentido de inserir ambientes de tensão com o leitor e que se propõe a ser um texto para que outros sejam escritos, não necessariamente por estes autores, para que, no encontro com as incompletudes inerentes de toda (re)criação escrita seja colocado no caminho da abertura para a alteridade de outras e sempre novas discussões.

Trazendo resquícios da interação com o leitor como em um diálogo, como já se disse, justificamos assim a ausência de subtítulos e seções para que as reflexões se instaurem dialogando umas às outras do início ao fim. Iniciemos com uma provocação:

O movimento e a inquietude são suas marcas. Ela não promete sossego, estabilidade, imobilidade. Ela desafia: a si mesma e a nós. Ela duvida, põe-se contra o bom senso, contra-argumenta. À medida que seguimos na leitura, somos instigados a partilhar desse movimento. (SALIH, 2013, extraído da orelha do livro)

O excerto anterior refere-se a um dos nomes mais mencionados nos estudos de gênero da atualidade: Judith Butler. Ela não é uma autora fácil de conceituar, tampouco pretende ser, não pretende resolver os problemas e as questões que mobiliza em suas análises e considera em suas análises o terreno da dialética enquanto movimento sempre incompleto e disposto à abertura de novos tensionamentos. A frase se refere à pensadora, mas poderia referir-se a Ney Matogrosso.

O verdadeiro nome do cantor e ator brasileiro Ney Matogrosso é Ney de Souza Pereira, natural de Mato Grosso do Sul. Ressalte-se que antes de se dedicar à carreira solo, era integrante do grupo Secos \& Molhados, na década de 1970, época em que decide seguir seu próprio rumo na Música Popular Brasileira, inaugurando um estilo próprio, pelas suas performances, digamos, incomuns nos shows. De acordo com a crítica musical, trata-se de uma das vozes mais brilhantes do país, tendo alcançado o sucesso e se mantendo na mídia até os dias atuais.

Dessa forma, a maquiagem e o vestuário exótico podem apontar para masculinidades subversivas ou fora do padrão desde a década de setenta até a contemporaneidade. O comportamento do cantor, as temáticas de suas músicas e os gestos transgressores fora dos palcos lhe valeram algumas ameaças do regime militar. Poder-se-ia aqui iniciar com uma frase: o que quer, o que pode este corpo? E os atos performativos de Ney podem apontar para múltiplas possibilidades no (des)encontro com os expectadores diante de suas apresentações. 
REVISTA X, Curitiba, volume 14, n.4,p. 240-255, 2019

O que teriam em comum então o cantor e Judith Butler? Ambos parecem se propor continuamente a reinvenção de suas propostas e o incerto é caminho das reticências presente em suas “obras”. É sobre esta relação que nos propomos aqui a falar. O recorte de análise será composto de fragmentos de uma entrevista com Ney Matogrosso para a Rolling Stone que apareceu nas páginas da revista em fevereiro de 2011. Por ser extraída de uma versão online, não há paginação e sempre que for extraída alguma parte deste material, a referência trará menção apenas ao ano em que foi veiculada. A escolha também se dá por causa da democratização do acesso aos leitores do presente texto à entrevista em questão, sendo a popularização da internet um "facilitador" do acesso, neste caso.

Em Foucault (1988), o prazer é sempre orquestrado por um conjunto de fatores. São forças, relações de poder que incindem sobre os corpos que buscam normatizar, regular, prescrever e tornar "naturalizados" os gestos coletivos em relação ao cuidado de si, já que "a compreensão que temos de nós mesmos como pessoas capazes de efetuar escolhas livres e autônomas é, ela própria, uma construção que nos permite ser governados" (MARSHALL, 2002, p. 22). Diferente do que se pode pensar que a criação de padrões de beleza opera de fora para os indivíduos, ela também opera dos indivíduos para consigo mesmo, e por causa da frequência com que os corpos são disciplinarizados, isso faz com que os espelhos reflitam sempre a falta. Então, os padrões de beleza e as normas de comportamento social passíveis de aprovação vão mudando com o passar do tempo enquanto evidência das relações de poder existentes em relação aos corpos enquanto objeto de julgamento do Outro (SILVEIRA; DUARTE, 2012). Além dos padrões de beleza, temos, conforme dissemos anteriormente, os gestos disciplinares/disciplinadores que entram em discursivização através do imaginário coletivo reforçando a naturalização de práticas que devem predominar em relação a outras.

Então, o sexo passa a ser visto como algo a ser normatizado e cada vez que entra em cena, aparece revestido de enunciados possíveis. O trabalho arqueológico (porque parte de uma escavação nas camadas descontínuas da história) sobre os enunciados possíveis de uma época torna possível investigar porque surgiu este enunciado e não outro em seu lugar? (FOUCAULT, 1995). Dessa forma, Foucault aponta em várias de suas palestras para a existência das relações entre poder e conhecimento.

Diferente do poder exercido por alguma autoridade de forma vertical sobre os corpos, existe um tipo de poder-conhecimento que não diz respeito ao conhecimento da 
verdade, mas remete à forma como o conhecimento circula e impõe efeitos no meio social, sobre os corpos e sobre o que (pensamos que) somos. Para Butler (2002), a forma como nos expressamos (performer) pode ser visto como efeito deste poderconhecimento. Foucault (1988) falou sobre o dispositivo da sexualidade, no sentido de haver práticas que tergiversam, cerceiam, constroem modos de olhar para a sexualidade que podem ser sempre outros modos, mas que aparecem como "evidentes", como se sempre tivessem existido, enquanto comportamentos "naturalizados" em oposição a outros.

No que concerne à sexualidade, é possível afirmar que ao longo da história, a sociedade tem criado normas como fator padronizador de condutas ligadas a comportamentos sexuais. Nessa busca por ditar regras de como o indivíduo deve se comportar, de acordo com a ordem vigente, tal imposição acaba por criar subjetividades ligadas à exclusão no que concerne à sexualidade, abolindo o que é diferente, não aceitável. Nesse contexto, Silveira (2018, p. 143) afirma acerca dos estudos de Butler alguns norteamentos:

Cabe ressaltar que a autora percebe a identidade como um processo, substituindo a ideia de identidade pela ideia de identificação e criticando dessa forma as fixações de identidades. Ao invés de identidades temos, portanto, processos de identificação. Em Butler [...] neste sentido, existem unidades provisórias e contingentes o que não significa afirmar a inexistência do sujeito, mas alertar para o fato de que ele não exista como algo estabilizado, pronto e acabado, apenas instituído socialmente a partir de unidades formadoras que o caracterizem visando engessar as descontinuidades e instabilidades inerentes às identificações que contradizem as fixações impostas.

Tomando o caminho da consituição de subjetividade ligada às performances corporais, como estilos de uma homossexualidade explícita em seus movimentos, Ney Matogrosso integra um perfil de sujeito que foge às regras comportamentais aceitas, que não se enquadra à ordem de acordo com as regras sociais padronizadas de comportamento. Essa classificação do que está ou não na regra da sociedade é advinda das relações de poder, que apela para a normalização e apresenta estranhamento pelo diferente, como conduta inaceitável que está fora da roda das subjetivações estabelecidas. "O poder seria, essencialmente, aquilo que dita a lei, no que diz respeito ao sexo. O que significa, em primeiro lugar, que o sexo fica reduzido, por ele, a regime binário: lícito e ilícito, permitido e proibido”. (FOUCAULT, 1999, p. 81). 
No que tange aos regimes de verdade ligados ao sexo propriamente dito, a interdição sempre tem o dominado como algo que não se pode manifestar perante o outro. O poder que aí impera o trata como norma social que impede o sujeito de manifestar seu desejo, de discurtir sobre o assunto, enfim retirar de seu contorno as máscaras que o conduzem a uma afirmação que deve ser escondida no seu íntimo. $\mathrm{O}$ sujeito artista em destaque, por meio de sua possibilidade artística, acaba por forjar essa exterioridade sexual estabelecendo uma relação entre a arte e a sexualidade, como possibilidade para se subjetivar em uma outra ordem. Assim, essa aliança entre o artístico e o sexual, cria resistência às leis estabelecidas, rompe com essas proibições que bloqueiam as manifestações, inclusive públicas, do apelo sexual que constituem sujeitos, pelo viés discursivo.

As normas sociais são colocadas em xeque pelo sujeito artista de forma a trilhar novas possibilidades de constituição subjetiva, cuja binaridade (homem e mulher; masculino e feminino) que dita papéis sociais bem demarcados são verdades dadas como modelo para constituição do sujeito. No caso do Ney, sendo do sexo masculino, mas com comportamento feminino, contradiz esses discursos normativos consolidados (usa saia, faz pintura no rosto, pratica nuances femininas no palco). Trata-se de uma manifestação da sexualidade de maneira singular que contraria os padrões vigentes, na esteira do que pode ou não ser manifestado, que acaba por criar uma descontinuidade de uma estrutura social de censura às práticas ligadas à sexualidade, isto é, de ter que ser explicitamente homem ou mulher.

Com efeito, uma coisa é uma regra de conduta; outra, a conduta que se pode medir a essa regra. Mas, outra coisa ainda é a maneira pela qual é necessário "conduzir-se" - isto é, a maneira pela qual se deve constituir a si mesmo como sujeito moral, agindo em referência aos elementos prescritivos que constituem o código. Dado um código de ação, e para um determinado tipo de ações (que se pode definir por seu grau de conformidade ou de divergência em relação a esse código), existem diferentes maneiras de "se conduzir" moralmente, diferentes maneiras, para o indivíduo que age, de operar não simplesmente como agente, mas sim como sujeito moral dessa ação. (FOUCAULT, 1998, p. 27)

Uma das preocupações do teórico citado é a prática de si, os modos como o sujeito se relaciona consigo mesmo e em relação ao outro, na vida coditiana, pelas práticas discursivas. As palavras citadas nos direcionam para as normas sociais como forma de se governar o indivíduo, isto é, estratégia de se interferir na conduta do outro, cujo código de regras funciona como uma ordem da qual não se pode escapar. As 
REVISTA X, Curitiba, volume 14, n.4,p. 240-255, 2019

proibições entram em cena nesse processo que governa o indivíduo para a lei do que seja verdadeiro para uma época e que todos devem seguir mais ou menos os mesmos padrões de subjetividade.

Nesse ínterim, vale ressaltar que, embora ao longo da história, inclusive ocidental, sempre houve classificações quanto aos modos de subjetivação, cujas identidades abrangem conjuntos de sujeitos ligados pelas mesmas práticas que os moldam, existem exceções quanto a essas uniformidades. No interior de qualquer grupo social existem diferenças identitárias que distinguem os sujeitos dos demais, inclusive se levarmos pelo lado individual. Nenhum sujeito é totalmente igual a outro, ainda que seja integrante de um grupo que seguem as mesmas regras e práticas discursivas.

O recorte analisado foi escolhido justamente para problematizar essa singularidade no contexto de identidades sexuais impostas socialmente. Não se trata simplesmente de um sujeito artista homossexual, pois nesse perfil existem vários, sendo que nosso interesse parte de um perfil incomum de modo de subjetivação em meio à comunidade LGBTT (lésbicas, gays, bissexuais, travestis e transgêneros) pelas suas performances que o excluem do senso comum, que o tornam inusitado frente aos demais e aos padrões sociais vigentes. Assim, afirma-se que se trata de um sujeito pautado pela "[...] atitude individualista, caracterizada pelo valor absoluto que se atribui ao indivíduo em sua singularidade e pelo grau de independência que lhe é atribuído em relação ao grupo ao qual ele pertence ou às instituições das quais ele depende". (FOUCAULT, 1985, p. 48).

Esse fazer-se um sujeito "anormal" frente aos demais pode ser entendido, então, como práticas discursivas que se caracterizam por certa individualidade, como práticas de si, que o filósofo citado denomina de constituição das subjetividades. Consequentemente atreladas a esse comportamento que expõe sua sexualidade, fora dos padrões cristalizados, estão as práticas de liberdade, que configuram um sujeito anormal, tendo em vista as relações de poder que o reprimem e o excluem, por assim dizer, pelo tratamento de subjetividades diferenciadas.

Ao tornar visíveis determinadas práticas em detrimento de outras, são apresentados modus operandi delimitados que estão associados aos modos de olhar para a sociedade e para os corpos e sobre como estes devem agir. Neste contexto, expressão e repressão tornam-se avessos de uma mesma moeda. Vejamos como isso funciona na prática através daquilo que Baudrillard (1997) chamou de supersimulação da feminilidade em consonância a um excerto da fala de Ney Matogrosso quando 
questionado sobre a possibilidade de que o excesso de nudez tenha mudado a forma como o jovem se relaciona com a arte. Diz o cantor:

Talvez sim. É muito louco eu estar falando isso, porque eu sou um artista que introduziu a sexualidade explícita na arte brasileira... Mas acho que tudo hoje é sexo. Quando eu fazia, estávamos em uma ditadura estúpida que mandava jogar pessoas vivas, de um avião, no mar. Então tinha um sentido. Hoje, nem se eu fizesse teria sentido. Há uma banalização da nudez, do sexo. É interessante poder se expressar, mas agora não é contra nada, é uma decadência generalizada. Sou uma pessoa muito liberal, acho que tudo pode, mas isso nem é um excesso de liberalidade, é mais uma vulgaridade que impera. Isso me incomoda. (VELOSO, 2011)

Baudrillard (1997), em relação ao excesso de nudez veiculado na mídia e nos tabloides mundiais diz que com o passar do tempo ocorreu uma banalização dos corpos, causado pela extrapolação da pornografia, o que entra em consonância com as palavras do artista sul-mato-grossense. Para Baudrillard (1997), a pornografia excessiva deixa de ser pornografia, por justamente anular-se pelos excessos. No entanto há uma ressalva: para o autor, é justamente esta banalização que pode ser muito perigosa, já que, no caso das mulheres, por exemplo, o padrão de mulher-objeto, veiculado pela mídia e incentivado pela indústria da moda, vai ditando regras e padrões que passam a (re)direcionar ações dos indivíduos para consigo mesmo e sobre seus comportamentos. Essa banalização da nudez faz com que haja um esvaziamento de discursos rumo à anulação dos efeitos da nudez, que passa a ser percebida como "normal" e, em consequência disso, vulgarizada. Também essa superexposição vai ao encontro das palavras do pensador Juremir Machado da Silva para quem, na atualidade, em que somos continuamente bombardeados de informações por todos os lados, em meio a navegações e naufrágios, as coisas passam a sumir por excesso de exposição, ao invés de reforçar sua presença.

Felizmente, para Foucault (1995), onde há relações de poder atuando sobre os corpos há resistência. Isso ocorre porque existe modo de escapar às normas estabelecidas pelos padrões "normais" tornando os corpos atravessados por um estado transitório em que continuamente torna-se necessário o reforço das discursivizações sobre o que é "aceitável" e o que é "estranho, diferente", já que os "sujeitos individuais ou coletivos têm diante de si um campo de possibilidades de diversas condutas, diversas reações e diversos modos de comportamento que podem acontecer" (FOUCAULT, 1995, p. 244). Então, Ney Matogrosso apresenta-se como o artista que introduziu a 
sexualidade explícita na arte brasileira. Se percebermos a utilização do termo "arte" poderíamos perceber a produção de sentidos aí evocados em consonância com o ato performativo descrito por Butler (baseado na teoria linguística de Austin). Sobre isso se tornam pertinentes as palavras de Paul Fry, que leciona na Universidade de Yale, na qual Butler foi professora.

Para o professor (FRY, 2013), a partir de Butler não se pode dizer que há sexualidade contínua e específica, mas reforçada com o passar do tempo através dos atos performativos. O que você pode fazer é expressar uma identidade repetindo, imitando e isso se assemelha a uma performance daquilo que somos (ou no que vamos nos constituindo enquanto indivíduos dotados de identidades passíveis de mudanças ${ }^{4}$ ). Dessa forma, o trabalho de Butler não é sobre a construção da identidade, nem sobre o controle da expressão, pois há algo difícil de apreender que está além da expressão, o que resta ao investigador é pensar sobre a natureza e os propósitos da expressão como um todo, então. Por isso, pensar na sexualidade é pensar em como os discursos vão dando contornos aos corpos e de que forma os gêneros são construções sociais reforçadas ou recalcadas com o passar do tempo. Em meio a tudo isso está o sujeito, não um ente com existência individualizada no mundo, mas, para Fernandes (2012), um sujeito cuja identidade é produzida a partir dos efeitos de uma exterioridade constitutiva. Isso implica em pensar, segundo o autor, no funcionamento dos discursos e seus efeitos na constituição dos sujeitos; assevera, pois, a subjetividade produzida pela exterioridade.

Cabe uma ressalva: discurso aqui não é sinônimo de dizer, de enunciado, de fala, mas algo que é exterior à língua, mas que precisa da língua para ter existência material (FERNANDES, 2008). Dessa forma, os sujeitos tomados como posição revelam posições em contraste que revelam lugares sociais e ideologicamente marcados, sendo a linguagem uma forma de materialização destes lugares. Falar em nudez, em sexualidade, em identidade torna-se, portanto, uma questão discursiva.

Em algum momento de sua aula, Paul Fry (2013) chama atenção a uma frase pronunciada por Butler em uma palestra: "desde os dezesseis anos, tenho sido uma lésbica". A partir disso, se propõem estudos de cunho filosófico sobre como os estudos de Butler ingressam nos terrenos de uma ontologia, partindo a versar sobre o ser. Colocamos em suspenso um pedaço da fala de Ney Matogrosso para retornar a ela em

\footnotetext{
${ }^{4}$ Essa ideia entra em consonância com os pressupostos foucaultianos, filósofo que considera o sujeito sempre em processo de constituição pelas práticas discursivas, pelas relações de saber e de poder que mudam de acordo com a história, constituindo identidades distintas como produto das transformações sociais vigentes.
} 
REVISTA X, Curitiba, volume 14, n.4,p. 240-255, 2019

seguida para entrar em diálogo com as reflexões que pretendemos expor neste momento: "É interessante poder se expressar, mas agora não é contra nada, é uma decadência generalizada". (VELOSO, 2011). Retornemos então ao fator ontológico em Butler e posteriormente sobre como as duas frases destacadas (a frase de Butler e a frase de Ney Matogrosso) podem dialogar neste sentido. Dissemos que os estudos de Butler (2003) passaram e ter caráter de reflexão sobre uma espécie de ontologia. Desde o início do texto, o fantasma da identidade retorna como algo impossível de negligenciar ou ocultar seja nos interditos, seja nos modos como ele vai deixando resquícios naquilo que é dito. Logo no início do texto partiu-se da menção do conceito que não pode ser percebido através da homogeneidade. Isso aponta para o terreno das instabilidades dos termos pelos quais as identidades são (des)construídas e vai ao encontro da afirmação de que a exterioridade produz subjetividades. Como sobre a exterioridade paira a possibilidade de vir a ser outra, o fantasma do devir precisa ser considerado ainda no que tange às identidades, já que, se a exterioridade do sujeito pode ser outra, outras podem ser as formas com que o sujeito se move no espaço de sua historicidade, do ambiente social e cultural em que vive.

O sujeito em Butler (2003), da mesma forma, não é um indivíduo, mas uma estrutura linguística em formação. Sob este prisma, a subjetividade não é um dado pronto e acabado, inerte de possibilidades e movências, uma vez que "o sujeito está sempre envolvido num processo de devir sem fim, é possível reassumir ou repetir a subjetividade de diferentes maneiras". (SALIH, 2013). Agora retomemos os enunciados extraídos da fala de Butler (destacadas pelo professor Paul Fry) e da fala de Ney Matogrosso. Quando Butler diz "desde os dezesseis anos tenho sido uma lésbica” ela traz consigo marcas de sua teoria reveladora do enaltecimento da importância dos gestos performativos na (des)construção da identidade de um sujeito. Para Fry (2013), ser algo é diferente de estar sendo algo, que parte da "encenação" do ser, que revela o movimento contínuo que parte de um início estabelecido (desde os dezesseis anos), mas não se fecha como um todo em si, já que a natureza do verbo revela um gesto inacabado.

Em relação à frase de Ney Matogrosso: "É interessante poder se expressar, mas agora não é contra nada, é uma decadência generalizada". (VELOSO, 2011). Podemos dizer que ela se apresenta relação de estranheidade ao que ele mesmo enunciou anteriormente: "sou um artista que introduziu a sexualidade explícita na arte brasileira..." Como aquele que se apresenta como o artista que introduziu a sexualidade explícita na arte brasileira, com o passar do tempo, passa a considerar exagerada a nudez devido à 
forma como é apresentada na atualidade? Ambos os exemplos apontam para a natureza dialética do devir. A ideia de processo ou de devir torna-se imprescindível para entender o tipo de ontologia que Butler (2003) propõe e estão embasadas, nos estudos da autora sobre a noção hegeliana de dialética.

$\mathrm{Na}$ dialética [...] propõe-se uma tese que é depois negada em sua antítese e resolvida numa síntese. Essa síntese ou resolução não é, entretanto, final, mas serve de base para a próxima tese, a qual mais uma vez leva à antítese e à síntese até que todo processo se inicie novamente. No modelo dialético de Butler, o conhecimento avança através da oposição e da negação, nunca alcançando uma certeza "absoluta" ou final, mas simplesmente propondo ideias que não podem ser fixadas como "verdades". (SALIH, 2013, p. 12)

Dessa forma, podemos dizer que, em Butler (2003), as questões permanecem em aberto, passíveis de retomadas posteriores e até mesmo desconstruções que subvertam as identidades iniciais daquilo que foi proposto anteriormente. Trata-se, como se procurou mostrar neste texto, do elogio da diferença e do ambiente de tensão possibilitado pelo diálogo entre temas, autores e gestos hermenêuticos sempre renovados, em que os leitores podem confrontar-se com os textos e modificar suas "verdades" entrando em processo de saberes em contínuo devir.

Outro elemento pode ser destacado em relação a Ney Matogrosso: a voz. Quem teve a oportunidade de ouvir em algum de seus CDs percebe que ela não traz vestígios de uma voz marcada pelo que a naturalização dos discursos sobre os gêneros no senso comum chamou, com o passar dos tempos, de masculinidade. Somada à maquiagem e aos atos que ele exerce no palco, temos elementos que o conservadorismo que se manifesta através dos sujeitos (o exterior produzindo subjetividades, como já se disse) classificaria como "impróprios", “contra a natureza do masculino", “anormal”. Estas atitudes trazem em si a pretensão de revelarem-se verdadeiras ou naturalmente "corretas" em relação àquilo que descrevem sob pretextos religiosos, morais, ideológicos.

Partindo para a dimensão de anormalidade, tendo em vista o objeto de estudo em questão, cujo sujeito é percebido como distinto dos comportamentos considerados socialmente como "normais", vale problematizar esse conceito e relacioná-lo com o corpus na perspectiva de Michel Foucault. Em Os Anormais, o referido filósofo propõe, em suas aulas no Collège de France, debater sobre a questão do exercício do poder no âmbito das classificações, das normalizações no campo psiquiátrico, esbarrando-se também no jurídico e adentrando na sexualidade, que é do nosso interesse para este trabalho. 
Esse exercício de poder sobre o dito "anormal", como o louco ou aquele que cometeu um crime, se baseia na ideia de correção, tornar os corpos dóceis para a convivência social. Vale destacar que essas normalizações entram no jogo dos regimes de verdade, como práticas discursivas que são consideradas socialmente como verdadeiras, a cada momento histórico vigente. As regras sociais, ou a norma como é considerada pelo teórico, entra no cenário de exercício do poder nos processos de normalização:

Em todo caso - e é a terceira ideia que acho ser importante - a norma traz consigo ao mesmo tempo um princípio de qualificação e um princípio de correção. A norma não tem por função excluir, rejeitar. Ao contrário, ela está sempre ligada a uma técnica positiva de intervenção e de transformação, a uma espécie de poder normativo. (FOUCAULT, 2001, p. 62)

Como já explanado, Ney Matogrosso é um sujeito que se encaixa na anormalidade, não apenas por se tratar de um homossexual, isto é, contra a heteronormatividade que é cristalizada socialmente, mas pela sua performance no interior dessa homossexualidade. Trata-se de uma prática incomum em relação aos demais sujeitos pertencentes às normas de condutas que os encaixam naquilo que é denominado como verdadeiro para uma época. Ainda que os tempos modernos proporcionam condições bastante vantajosas e que a aceitação ao diferente tem avançado, o anormal é percebido socialmente, aquilo que está fora dos padrões que uniformiza os sujeitos numa determinada identidade cultural.

O estudioso citado sublinha a questão da norma que sempre existiu na vida social de seus sujeitos. No que concerne à qualificação e correção, o sujeito objeto desta pesquisa pode ser encaixado como identidade subversiva, pois seu lugar é na margem das práticas normais da sociedade vigente. Embora o teórico aborde o princípio de correção no âmbito da loucura e da criminalidade, esse exercício de poder poderia ser aplicado também sobre o sujeito considerado como subversivo pela sexualidade, uma vez que não se encaixa na normalidade socialmente aceita. "É esse conjunto de ideias que eu gostaria de tentar aplicar historicamente, essa concepção ao mesmo tempo positiva, técnica e política da normalização, aplicando-a ao domínio da sexualidade". (FOUCAULT, 2001, p. 62).

Esses exercícios de poder que levam os sujeitos a se subjetivarem de acordo com as verdades instauradas, as regulações, normalizações, apontam para modos de subjetivação distintos numa mesma formação social. Essa "anormalidade" de Ney 
Matogrosso nada mais é que um exercício de resistência aos padrões pré-estabelecidos de subjetivação, por um processo de individualização fora das regras historicamente impostas.

Isto posto, para Butler (2003), bem como para Foucault (1995), tratar-se-ia de honestamente mostrar estes termos e os lugares onde eles produzem efeitos de sentido para contextualizar e sujeitá-los, então, à análise e contestação. Isso leva a perceber os modos como são produzidas as subjetividades (e de como foram sendo construídas com o passar dos anos) através de categorias pelas quais o sujeito é descrito como "gay", "heterossexual", "bissexual", "transexual", "branco", "negro", como se os termos trouxessem atrelados a si características "inatas". Trata-se, portanto, de investigar o que está funcionando por meio da ideologia de outros termos, como "verdade", "adequado", "inadequado", "correto", "errado" e em como eles entram em circulação no meio social, atuando na produção de identidades (bem como há existência de sujeitos subversivos em relação às relações de poder que buscam legitimar padrões identitários em detrimento de outros).

Sobre o sujeito ainda cabe outra contribuição. Se em Butler (2003) e em Foucault (1995) a produção de subjetividades é um processo que deve ser analisado a partir de contextos históricos e discursivos específicos (e na sua relação com outros contextos), em Derrida (2005), o significado é apresentado como um evento ocorrido em uma cadeia citacional ininterrupta, sem origem nem fim, em que os sujeitos se inserem. Significa que todo texto é interminável e modificável, transformável e desconstruível, seja pelo que veio antes em relação ao que veio depois, seja em relação aos diferentes modos de olhar que vão sendo tecidos sobre o mesmo objeto observado. Por isso, os sujeitos podem vir a ser outros, estando em processo de contínuo devir.

No exemplo da frase de Butler (2003), o termo "tem sido" evoca a presença de uma oposição (tem sido em oposição ao que é), pois há um elemento de encenação que se infiltra na ontologia (FRY, 2013). Dessa forma, "tenho sido uma lésbica" aponta para, em certo aspecto àquilo que sou no instante em que enuncio, mas também ao que tenho sido, a forma como tenho me expressado, como se expressássemos papéis como em uma performance.

Assim, da mesma forma como Butler (2003) expressa sua identidade através do ato performativo, Ney Matogrosso revela as nuances e contrastes em relação ao olhar tecido sobre a nudez que remete a diferentes épocas e revela o sujeito historicamente situado no tempo. Como podem ser aproximados ainda mais alguns nomes 
REVISTA X, Curitiba, volume 14, n.4,p. 240-255, 2019

mencionados neste texto? Tanto Foucault quanto Butler quanto Ney Matogrosso produziram obras que continuamente produzem sentidos de desestabilização da norma heterossexual negando, de certo modo, a autenticidade de discursos naturalizados com o tempo, deixando à mostra os fantasmas das masculinidades subversivas, ou ainda, segundo Butler (2003), criticando a "originalidade" dos papéis de gênero privilegiados.

Em outras palavras: quem disse que a heterossexualidade veio primeiro? Quem disse que há comportamentos "adequados" direcionados a gêneros "específicos"? Por trás dos efeitos destes questionamentos estão "verdades" que se impõem como autoevidentes tornando-se veículos ideológicos de opressão a grupos sociais minoritários, marginalizados pela força dos efeitos que as palavras excludentes daqueles que não se "adequam" aos comportamentos "naturais" evocam. O desejo, ao término de um texto que se propôs desde o início incompleto e atravessado pela abertura a outros diálogos (e que aqui preserva este intuito) é de que as palavras mais sombrias sobre os corpos e as subjetividades não remetam ao desaparecimento das resistências, mas a sobrevivências de sujeitos apesar de tudo, com suas roupagens de vagalumes (DIDIHUBERMAN, 2011) a mostrar que na reverberação das "certezas”, há sempre algo que escapa...

A proposta de problematização sobre a identidade do artista brasileiro referido nos convida a adentrar pelo universo das diferenças subjetivas, pautando-se naquilo que pode ser denominado de "anormal', "diferente", tomando as considerações foucaultianas em relação às constituições subjetivas, aos corpos, tendo em vista as relações de poder que exercem função de regular e normalizar os sujeitos. Pelas análises tecidas ao longo das reflexões, é evidenciado um modo de subjetivação que vai de encontro às normalidades vigentes, ainda que no campo da homossexualidade, pois de acordo com os padrões pré-estabelecidos das formas de devir instaurados na sociedade, Ney Matogrosso apela pelo exagero e extravagância tanto no que concerne a suas performances.

O corpo é uma instância considerável no processo de constituição subjetiva do sujeito, assim como Foucault $(1984 ; 2004)$ o toma para seus estudos, podendo ser percebida em grande parte de suas formulações. Nesse contexto, a sexualidade entra em cena como elemento considerável nesse âmbito de subjetividade que aponta para práticas discursivas constitutivas do sujeito, bem como apontado na entrevista com o cantor supracitado. A maneira singular do cuidado de si em relação a seu corpo aponta para a transgressão, incomum em relação ao que é tomado como normal na sociedade, 
resultando em um sujeito que se constitui de forma subversiva, cuja arte funciona como suporte para suas práticas. Sua performance acaba por forjar sua identidade por meio do estabelecimento de uma relação entre a homossexualidade e a arte, sobretudo como cantor, cujo palco serve de base para suas práticas discursivas e é onde suas subjetividades são evidenciadas.

Eu compreendo o mal-estar de todos esses. Foi sem dúvida, muito doloroso, para eles, reconhecer que sua história, sua economia, suas práticas sociais, a língua que falam, a mitologia de seus ancestrais, até as fábulas que contavam na infância, obedecem a regras que não se mostravam inteiramente à consciência; eles não desejam ser privados, também e ainda por cima, do discurso em que querem poder dizer, imediatamente, sem distância, o que pensam, creem ou imaginam; vão preferir negar que o discurso seja uma prática complexa e diferenciada que obedece a regras e a transformações analisáveis a ser destituídos da frágil certeza, tão consoladora, de poder mudar, se não o mundo, se não a vida, pelo menos seu "sentido", pelo simples frescor de uma palavra que viria apenas deles mesmos e permaneceria o mais próximo possível da fonte, indefinidamente. Tantas coisas em sua linguagem já lhes escaparam: eles não querem mais que lhes escape, além disso, o que dizem, esse pequeno fragmento de discurso - falado ou escrito, pouco importa- cuja débil e incerta existência deve levar sua vida mais longe e por mais tempo. (FOUCAULT, 1995, p. 254)

\section{REFERÊNCIAS}

BAKHTIN, M. Estética da criação verbal. Trad. do russo: Paulo Bezerra. 6. ed. São Paulo: Editora WMF Martins, Fontes, 2011.

BAUDRILLARD. J. Tela total: mito-ironias da era virtual da imagem. Porto Alegre: Sulina, 1997.

BUTLER, Judith. Cuerpos que importam: sobre los limites materiales y discursivos del "sexo". Buenos Aires: Paidós, 2002.

BUTLER, J. Problemas de gênero: feminismo e subversão da identidade. Rio de Janeiro: Civilização Brasileira, 2003.

DERRIDA, J. A farmácia de Platão. Trad. Rogério da Costa. São Paulo: Iluminuras, 2005.

DIDI-HUBERMAN, G. A sobrevivência dos vagalumes. Trad.: Vera Casa Nova; Márcia Arbex. Belo Horizonte: Editora da UFMG, 2011.

FERNANDES, C. A. Análise do discurso: reflexões introdutórias. 2. ed. São Carlos: Claraluz, 2008.

FERNANDES, C. A. Discurso e sujeito em Michel Foucault. São Paulo: Intermeios, 2012. 
FOUCAULT, M. A arqueologia do saber. Trad. Luiz Felipe Baeta Neves. Rio de Janeiro: Forense universitária, 1995.

FOUCAULT, M. História da sexualidade I: a vontade de saber. 13. ed. Rio de Janeiro, Edições Graal, 1988.

FOUCAULT, M. História da Sexualidade II: o uso dos prazeres. 8. ed. Rio de Janeiro: Graal, 1984.

FOUCAULT, M. História da Sexualidade III: o cuidado de si. 8. ed. Rio de Janeiro: Graal, 1985.

FOUCAULT, M. Os Anormais: curso no Collège de France (1974-1975). Tradução Eduardo Brandão. São Paulo: Martins Fontes, 2001.

FOUCAULT, M. O uso dos prazeres e as técnicas de si. In: MOTTA, M. B. (Org.). Ética, sexualidade, política. Rio de Janeiro: Forense Universitária. (Ditos e escritos, vol. V), 2004, p. 192-217.

FOUCAULT, M. "O sujeito e o poder". In: DREYFUS, H.; RABINOW, P. Michel Foucault: uma trajetória filosófica para além do estruturalismo e da hermenêutica. Rio de Janeiro: Forense Universitária, 1995, p. 231-49.

FRY, P. Queer Theory and Gender Performativity. In: Open Yale courses, 2013. Disponível em: $<<$ https://oyc.yale.edu/english/engl-300/lecture-23 >> . Acesso em: nov. 2018.

MARSHALL, J. D. "Governamentalidade e Educação liberal”. In: DA SILVA, Tomaz Tadeu (Org.). O sujeito da Educação. Petrópolis: Vozes, 2002, p. 21-34.

MOITA LOPES, L. P. (Org.) Por uma Lingüística Aplicada Indisciplinar. São Paulo: Parábola Editorial, 2006.

VELOSO, B. Incansável, artista lança novo disco ao vivo e se prepara para aparecer nos cinemas [entrevista com Ney Matogrosso] Roling Stone. ed. 53, fevereiro de 2011.

SALIH, S. Judith Butler e a teoria Queer. Trad. E notas: Guacira Lopes Louro. Belo Horizonte: Autêntica, 2012.

SILVEIRA, E. L.; DUARTE, A. M. S. O discurso e as (des)identificações: reflexões acerca do feminismo e das vozes de resistência na atualidade. In: Rascunhos Culturais. Coxim, MS, vol. 3, nº 6, jul-dez 2012, pp. 143-164.

SILVEIRA, E. L. A universalidade desmantelada e as derivas do gênero: Foucault, Butler e as sexualidades insurgentes. Interfaces (Unicentro), v. 9, n. 2, p. 141-162, jul./ago./set. 2018. 